\title{
Analysis Technology Structure Reengineering Towards Quality of Service (Case Study in ITPC Busan)
}

\author{
*Kalfajrin Kurniaji \\ ${ }^{I}$ Management Department, Faculty of Business, Nusa Putra University \\ *Corresponding author.E-mail: kalfajrin.kurniaji@nusaputra.ac.id
}

\begin{abstract}
ITPC Busan is the representative of the Indonesian Ministry of Trade in South Korea. The institution evaluated technology structure to improve the quality of service. It is necessary to implement business process reengineering of the physical/technical layer. The population is costumer of ITPC Busan divided as Indonesian exporters and South Korean importers 129 companies. Based on the sample calculations, it acquired 98 companies distributed proportionally. This research used the method of observation, including descriptive verification. Data collection techniques are interviews and online questionnaires. To measure the magnitude of the effect of technology reengineering structure and quality of service. The result describes that technological structure reengineering includes web-based, social media, and computer-based structures. The effectiveness of technology reengineering is suitable to the excellent direction, the significance of quality of services is good, and technology structure reengineering has a positive influence on the quality of service.
\end{abstract}

Keywords: Financial Ratio, Liquidity and Current Ratio.

\section{INTRODUCTION}

Global economic conditions led to a decline in the trade balance between Indonesia and South Korea. The climate of business competition between countries makes the government and companies constantly strive to improve competitiveness in the global market.

ITPC Busan is a public organization under the supervision of the Ministry of Trade of Indonesia, which functions as a representative trade office in South Korea, which was established in 2009. One of the primary duties is to provide trade information services between Indonesia-South Korea. The institution operated its service with methods that tend to be conservative and less dynamic towards technological developments. This is marked by the lack of innovation and renewal of the central business processes without involving the latest technology. Top management assumes that the function must be evaluated to improve the quality of service performance. Several aspects were reviewed and deemed ineffective, so they had to apply business process reengineering.
The development of information technology today has changed the business paradigm and impacted scientific development. The internet makes the world seem flat and narrow because information can develop and flow very quickly. This makes the international trade situation more dynamic. Importers can easily access through the internet exporter companies worldwide to fulfill their needs in the South Korean market in a relatively short time. The utilization of information technology in business processes has made a paradigm shift in various aspects of a business. Speed and accuracy are important factors in winning the increasingly competitive business competition between countries.

\section{LITERATURE REVIEW}

Business process reengineering is a fundamental review and radical redesign of organizational processes to achieve dramatic improvements in terms of performance such as cost, service, and speed [1]. Business process reengineering is divided into nine dimensions classified into three layers, where the most concentrated and easily engineered layer is the 
Physical/Technical layer [7]. The organization or institution often finds initial assumptions about the process that is no longer valid.

The world is dynamic, where a customer wants, technology, products, and product mix are changing. Therefore, the process is redesigned or often also called reengineering [2]. Reengineering is radically rethinking and redesigning business processes to achieve dramatic performance improvements [3].

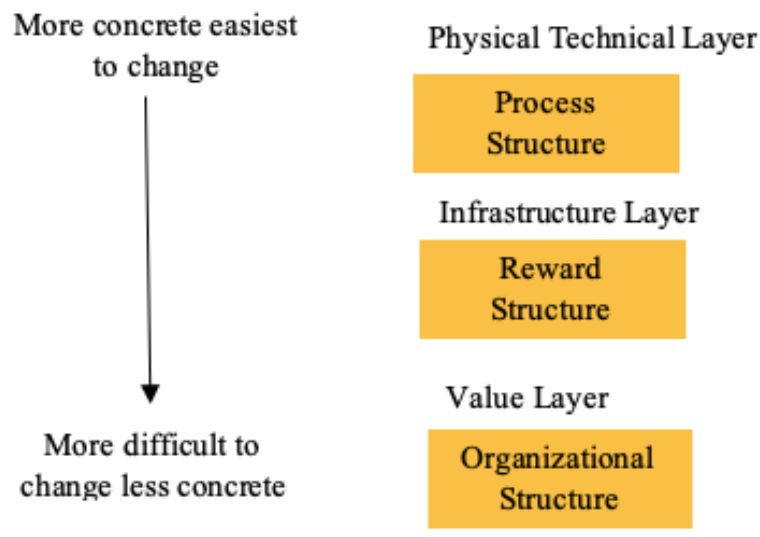

Figure 1. Dimension of Business process reengineering

The division of dimensions into several layers is intended to make it easier for organizations to understand the nature of each size in terms of its ability to change. Physical/technical layer (the most visible and concentrated physical/technical layer.

\subsection{The Technology Structure in the Physical/ Technical layer}

The physical and technical structure of the organization is easier to identify, but it is not enough to focus reengineering efforts only on that structure [7].

The impact of information technology on business success is understandable. It is essential to understand the benefits and limits of integrating information technology with work processes. The technology structure consists of communication devices, network systems, and computer systems designed to support the process structure. The technology structure can be in the form of local and international communication network system devices, imaging systems, and mobile communication networks, which have the potential to reduce communication gaps in organizations [4]. An interconnected database system and advanced software languages and tools can provide faster and cheaper administrative and control actions.

A successful reengineering initiative is business-driven, not technology-driven. It is
The dimensions of business process reengineering are the physical, technical, infrastructure, and value layers. The physical, technical layer is the dimension the organization should focus on and the easiest to reengineer. The Physical-Technical layer includes three indicators: process structure, technology structure, and organization structure [7].

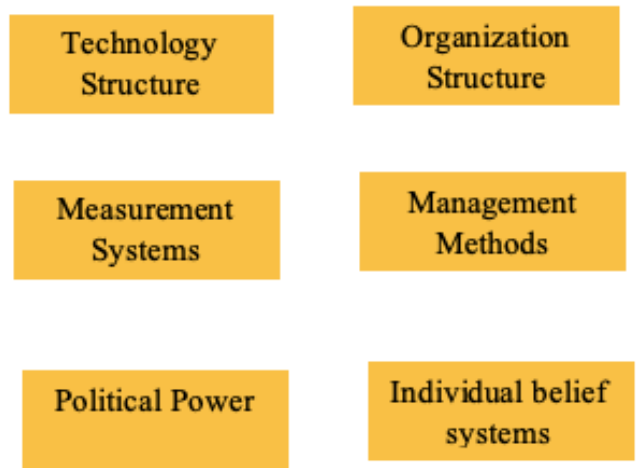

technology-enabled. Thus, technology should be used to improve business performance, and the application of technology should not take precedence in reengineering projects [8]. On the other hand, reengineering is a technical task such as activities, processes, technological structures, automation, and organization. When the idea came, people thought of "process reengineering." Still, unfortunately, the definition of reengineering has been significantly misunderstood by most of those who think about it, following the introduction and publication of concepts. Many people believe that reengineering is changing how specific jobs are done through technology. This is not true because technological change is only one part of the story of radical improvement.

\subsection{Quality of service}

The performance measurement process is needed to determine the level of success or achievement of the company's performance. One of the measures used in the performance measurement process is the Key Performance Indicator (KPI). It is an indicator used to determine how far the company's strategy has been carried out in following its vision and mission [6].

The public organization has difficulties finding suitable performance measurement tools. A public organization's primary purpose and mission are to meet the needs and protect the public interest. 
Indicators or criteria for the performance of public organizations are productivity, quality of service, responsiveness, responsibility, and accountability [5].

The quality of service tends to become increasingly important in explaining the performance of public service organizations. Community satisfaction can be a parameter to assess the performance of public organizations.

Service quality is an adjustment to the details (conformance to specification) where this quality is seen as the degree of excellence to be achieved, and continuous control is carried out in achieving these advantages to meet the needs of service users [9]. Service is a response to organizational needs only met if service users get the product they want.

The quality of public services indicates a service activity carried out by a service provider, which in this case is the government, to market or to distribute products by prioritizing the satisfaction and expectations of the community as customers, which in this case are those who are ordered, following service standards. And the principles of public service. One organization's quality of service standards may not apply to other organizations. Because basically, the service standards used are different, depending on the policies and directions of the organization.

\section{RESEARCH METHODS}

The research method used is observation, but the author took the initiative to add descriptive and verification processes to strengthen the research.

The type of data in this study consists of data about the general characteristics of the Indonesian Trade Promotion Center Busan, South Korea, and data for each of the variables studied. While research data sources are sources where the data needed to discuss research, problems are obtained directly (primary data) or indirectly (secondary information).

The sampling method used is Proportional Random Sampling; it is said to be proportional because the sample members consider the elements or categories in the research population. Companies are selected as respondents, where the sample is taken randomly using the entire population of 129 and then given to the company as much as 98 times (number of pieces). The people in this study were ITPC Busan South Korean customers consisting of Indonesian exporters and South Korean importer companies, with 668 companies.

The primary tool used for data collection in this study is a questionnaire used to collect preliminary data. The questionnaire distributed to the respondents had provided the answers, so the respondents had to choose the option. The construct of a closed questionnaire item for each variable is in the form of questions or statements about the nature and characteristics of each variable, accompanied by five alternative answers (Likert scale). The number of items for each variable is different according to the measured properties and characteristics.

\section{RESULTS AND DISCUSSION}

\subsection{Technology Structure Reengineering}

Business process reengineering is one of the methods in applying the latest technology in assisting business processes. Initially, ITPC Busan only operated business processes with a limited technology structure in the form of email and telephone, computer system facilities for database processing with supporting software, such as Microsoft Office. Table 1 below illustrates the technology structure of Busan's ITPC before business process reengineering.

Table 1. ITPC Busan's Technology Structure Stage

\begin{tabular}{|c|c|l|l|}
\hline \multirow{2}{*}{} & \multicolumn{3}{|c|}{ Description of technology structure } \\
\cline { 2 - 4 } & $\begin{array}{c}\text { Analyze Stage (before } \\
\text { BPR) }\end{array}$ & Redesign Stage (BPR process) & $\begin{array}{c}\text { Implementation Stage (Process } \\
\text { \& after BPR) }\end{array}$ \\
\hline \multirow{2}{*}{$\begin{array}{c}\text { Web-based } \\
\text { communication } \\
\text { facility }\end{array}$} & - & Website & Website \\
\cline { 2 - 4 } $\begin{array}{c}\text { Social } \\
\text { mediabased } \\
\text { communication }\end{array}$ & - & Smatphone app & Smartphone app \\
\cline { 2 - 4 } & - & Facebook Fan page & Facebook Fan page \\
\cline { 2 - 4 } & - & Instagram & Instagram \\
\hline
\end{tabular}




\begin{tabular}{|c|c|l|l|}
\cline { 2 - 4 } & - & Twitter & - \\
\cline { 2 - 4 } & - & Alibaba & - \\
\hline \multirow{2}{*}{$\begin{array}{c}\text { Computerbased } \\
\text { communication } \\
\text { facility }\end{array}$} & - & Digital brochure & Digital brochure \\
\cline { 2 - 4 } & - & Backoffice app & Backoffice app \\
\hline
\end{tabular}

\subsubsection{Web-based Communication Reengineering}

\subsubsection{Website}

ITPC Busan started to design the website with the domain address www.itpc-busan.kr. The website design is based on the Indonesian Ministry of Trade with the domain address www.kemendag.go.The website provides many features and trade information content that anyone can access. The ITPC Busan website has three language options: Bahasa, English, and Korean. As for the completeness of the content, the website has rich content in English, but some of the range hasn't been translated into Korean. This is an aspect that is currently being pursued in achieving improvement.

Data are a classic problem in Indonesia, and ITPC Busan has a mechanism to overcome this. The website only shows data validated by staff in the directory of Indonesian exporters. This was appreciated by the Directorate General of National Export Development by presenting the achievement at the annual meeting of ITPC Directors. Although the data submitted was limited, the validity of the data is good.

\subsubsection{Smartphone Application}

The development of the digital world encourages ITPC Busan to further develop automated communication devices in presenting the information. One of the rapidly growing technologies is smartphones. This tool helps humans with a relatively easy and fast process in many ways. The strengthening for validating database for the website, ITPC Busan then developed a smartphone application to deliver current information. The application can be found on the Playstore and Apple store by typing the keyword ITPC Busan in the search field. This application is specifically designed to support both Android and iOS operating systems.

\subsubsection{Social Media-Based Tools}

ITPC Busan optimizes the internet network to convey trade information so that it is faster and more widespread. After re-engineering web-based communication tools, ITPC Busan began to be active in social media, to post many contents about trade. And then, ITPC Busan designed several social media accounts used explicitly by ITPC Busan employees in presenting information and promoting Indonesian products include Facebook, Instagram, and Youtube channels.

1) Facebook fan page

Facebook is currently the most prominent social media globally, with 1.97 billion active users per month. Indonesia and South Korea are countries whose citizens use social media. In response to this phenomenon, ITPC Busan created a Facebook fan page account as a tool in delivering trade information. The ITPC Busan fan page currently has more than 4.200 followers with an average reach of 2002,000 per post. The address for the ITPC Busan fans page is https://web.facebook.com/itpcbusan.fp.

Facebook is also optimized for ITPC Busan as a communication medium. ITPC Busan uses a boosting service on some important content so that the content can appear randomly to the intended target account. Several Indonesian exporting companies and South Korean importers established initial communication via Facebook message inboxes.

2) Instagram

Instagram is a photo-sharing application that allows users to take photos, apply digital filters, and share them on various social networking services. Currently, Instagram is the most popular social media for young people after Facebook. Instagram features that are simple and only highlight image content make Instagram a powerful promotional medium in offering products online. The ITPC Busan Instagram is mainly filled with pictures of Indonesian products, those available in the Busan ITPC display room, products that have entered the Korean market, and products from the inquiry process (offers) from Indonesian exporting companies. ITPC Busan's Instagram has been active; the number of followers is 4.934 accounts. 
3) Youtube Channel

Youtube is a video service provider portal that has become a medium for sharing various video content. Youtube has become a new trend where everyone can watch and share videos. Youtube has also become one of the effective promotional media, considering that the internet traffic on this site is very dense. ITPC Busan Youtube is also used to connect to one of the video columns on the website. Youtube ITPC Busan mainly provides documentation of activities and promotions of certain products. In addition to promotional videos regarding Indonesian trade, Youtube ITPC Busan Busan is also filled with Indonesian promotional videos. The video depicts the beauty and uniqueness of nature and culture, and it is optimized as a medium to introduce Indonesia with its wealth. The number of videos is 58 , with 49.977 viewers covering all videos.
4) Digital Brochure

ITPC Busan digital brochure is the latest medium in helping to present trade information. The initial idea of this digital brochure was when ITPC Busan could no longer accommodate physical brochures sent by Indonesian exporting companies to be introduced to South Korean importing companies. The Director finally decided to digitize the scattered brochures into a touchscreen computer that can be displayed both at trade fairs and in front of the office as an automatic information search medium.

\subsection{Data Analysis}

\subsubsection{Technology Structure Reengineering}

The technology structure reengineering includes automated communication tools, and the cast is represented by twenty-six question items.

Table 2. Responses on the technology structure reengineering

\begin{tabular}{llcccc}
\hline \multicolumn{5}{c}{ Variable technology structure reengineering } \\
\hline Score & Response & Weight & Freq & $\%$ & Fx Weight \\
\hline 1 & Strongly & 1 & 23 & $1 \%$ & 23 \\
& Disagree & & & & \\
2 & Disagree & 2 & 284 & $11 \%$ & 568 \\
3 & Neutral & 3 & 1014 & $40 \%$ & 3042 \\
4 & Agree & 4 & 870 & $34 \%$ & 3480 \\
5 & Strongly & 5 & 357 & $14 \%$ & 1785 \\
& Agree & & & & 8898 \\
\hline Total & & 2548 & $100 \%$ & 7754 \\
\hline
\end{tabular}

Based on the table 2, score calculation can be made, the score value $\mathrm{x}$ (number of respondents $\mathrm{x}$ number of items). So that it can be seen that the lowest score is $1 \times(98 \times 26)=2,548$, while the highest score is $5 \times(98 \times 26)=12,740$ with a range of 2,038.4 If the position of the ideal influence score is described in the interpretation scale as follows:

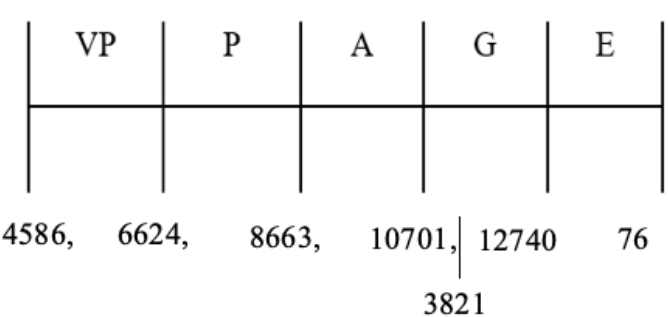

Figure 2. Score's range regarding the technology structure reengineering

The figure 2 shows that the majority of consumer responses regarding the reengineering 
of the technology structure is good with a total score of 8,868 and close to the middle line between good and excellent.

The description of the reengineering of the technology structure is presented based on the respondent's interpretation of each indicator as follows:

\subsubsection{Web-Based Communication Tools Reengineering}

Web-based communication tools are represented by twelve question items which are divided into websites and smartphone applications.

Table 3. Responses to the web-based communication tools re-engineering

\begin{tabular}{|c|c|c|c|c|c|}
\hline \multicolumn{6}{|c|}{ Variable web based communication reengineering } \\
\hline Score & Response & Weight & Freq & $\%$ & $\begin{array}{c}\text { Fx } \\
\text { Weight }\end{array}$ \\
\hline \multirow[t]{2}{*}{1} & Strongly & 1 & 14 & $1 \%$ & 14 \\
\hline & Disagree & & & & \\
\hline 2 & Disagree & 2 & 119 & $10 \%$ & 238 \\
\hline 3 & Neutral & 3 & 502 & $43 \%$ & 1506 \\
\hline 4 & Agree & 4 & 350 & $30 \%$ & 1400 \\
\hline \multirow[t]{2}{*}{5} & Strongly & 5 & 191 & $16 \%$ & 955 \\
\hline & Agree & & & & \\
\hline & Total & & 1176 & $100 \%$ & 4113 \\
\hline \multicolumn{2}{|c|}{ Average } & & & & 3548 \\
\hline
\end{tabular}

Based on the table 3, score calculation can be made, the score value $x$ (number of respondents $x$ number of items). So it can be seen that the lowest score is $1 \times(98 \times 12)=1.176$, while the highest score is $5 \times(98 \times 12)=5.580$, with a range of 940.8 . If the position of the ideal influence score is described in the interpretation scale as follows:

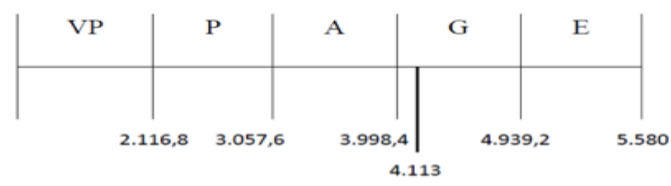

Figure 3. Score's range regarding the web-based communication tools re-engineering

The figure 3 shows that the majority of consumer responses regarding the reengineering of web based communication devices is good with a total score of 4,113 . The position of the line is at the beginning of good line towards excellent direction.

\subsubsection{The Social Media-Based Communication Devices Reengineering}

The social media-based communication reengineering is represented by eleven question items which are divided into Facebook Fan pages, Instagram and Youtube channel:

Table 4. Responses to the social media-based communication reengineering

\begin{tabular}{cccccc}
\hline \multicolumn{5}{c}{ Variable Social Media Reengineering } \\
\hline Score & Respons & Weigh & Freq & $\%$ & Fx \\
& $\mathrm{e}$ & $\mathrm{t}$ & & & Weight \\
\hline 1 & Strongly & 1 & 6 & $1 \%$ & 6 \\
& Disagree & & & & \\
2 & Disagree & 2 & 121 & $11 \%$ & 242 \\
3 & Neutral & 3 & 371 & $34 \%$ & 1113
\end{tabular}




\begin{tabular}{cccccc}
4 & Agree & 4 & 440 & $41 \%$ & 1760 \\
5 & Strongly & 5 & 140 & $13 \%$ & 700 \\
& Agree & & & & \\
\hline \multirow{2}{*}{ Total } & 1078 & $100 \%$ & 3821 \\
Average & & & & 3408 \\
\hline
\end{tabular}

Based on the table 4, score calculation can be made, the score value $\mathrm{x}$ (number of respondents $\mathrm{x}$ number of items).

So it can be seen that the lowest score is $1 \mathrm{x}$ $(98 \times 11)=1,078$, while the highest score is $5 \times(98$ $x 11)=5,390$, with a range of 862.4.

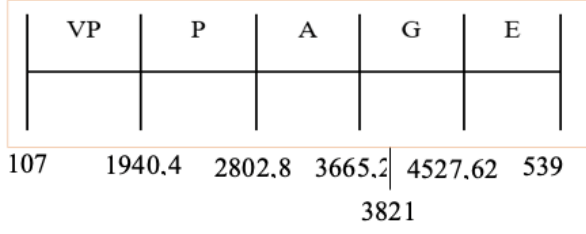

Figure 4. Score's range regarding the social media reengineering

The figure 4 shows that the majority of consumer responses regarding the social media based communication re-engineering is good with a total score of 3,821 . The position of the line is at the beginning of good line towards excellent direction.

\subsubsection{The Computer Based Communication Reengineering}

The computer-based reengineering is represented by three question items with products in the form of digital brochures.:

Table 5. Responses to the computer-based communication reengineering

\begin{tabular}{llllll}
\hline \multicolumn{5}{c}{ Variable Social Media Reengineering } \\
\hline Score & Response & Weight & Freq & $\%$ & Fx \\
& & & & & Weight \\
\hline 1 & Strongly & 1 & 3 & $3 \%$ & 3 \\
& Disagree & & & & \\
2 & Disagree & 2 & 0 & $15 \%$ & 90 \\
3 & Neutral & 3 & 141 & $34 \%$ & 423 \\
4 & Agree & 4 & 80 & $28 \%$ & 320 \\
5 & Strongly & 5 & 26 & $20 \%$ & 230 \\
& Agree & & & & 1037 \\
\hline Total & & & 298 & $100 \%$ & 3616 \\
\hline Average & & & & &
\end{tabular}

Based on the table 5, score calculation can be made, the score value $x$ (number of respondents $x$ number of items). So it can be seen that the lowest score is $1 \times(98 \times 3)=294$, while the highest score is $5 \times(98 \times 12)=1,470$ with a range of 253.2 .

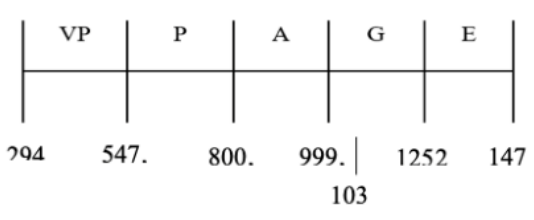

Figure 5. Score's range regarding the Computer based reengineering 
The figure 5 shows that the majority of consumer responses regarding the computer-based reengineering is good with a total score of 1,037 . The position of the line is at the beginning of good leading to excellent direction.

\subsection{Service Quality}

Service quality is represented by eight question items covering tangible and reliability.

Table 6. Responses to the Quality of Service

\begin{tabular}{cccccc}
\hline \multicolumn{5}{c}{ Variable Social Media Reengineering } \\
\hline Score & Respons & Weigh & Freq & $\%$ & Fx \\
& $\mathrm{e}$ & $\mathrm{t}$ & & & Weight \\
\hline 1 & Strongly & 1 & 7 & $1 \%$ & 7 \\
& Disagree & & & & \\
2 & Disagree & 2 & 32 & $5 \%$ & 64 \\
3 & Neutral & 3 & 251 & $43 \%$ & 753 \\
4 & Agree & 4 & 201 & $34 \%$ & 804 \\
5 & Strongly & 5 & 97 & $16 \%$ & 485 \\
& Agree & & & & \\
\hline \multicolumn{7}{c}{ Total } & & 588 & $100 \%$ & 2113 \\
\hline
\end{tabular}

Based on the table 6 , score calculation can be made, the score value $x$ (number of respondents $x$ number of items). So it can be seen that the lowest score is $1 \times(98 \times 6)=588$, while the highest score is $5 \times(98 \times 11)=2,940$, with a range of 470.4 .

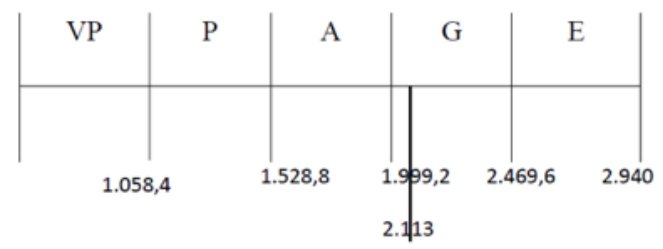

Figure 6. Score's range regarding the quality of service

The Figure 6 shows that the majority of consumer responses regarding the quality of service is good with a total score of 2.113. The position of the line is at the beginning of good leading to excellent direction.

\section{CONCLUSION}

Based on the results and discussion, the following conclusions can be drawn that technology structure reengineering in ITPC Busan includes: Web-based structure, Social media-based structure, Computer-based facility to increase the Quality of service. The effectiveness of technology reengineering is suitable to the excellent direction, The efficacy of web-based structure reengineering is ideal to the superb advice, The effectiveness of social media-based structure reengineering is perfect to the perfect guide, The efficacy of computer-based structure reengineering is suitable to the excellent movement, The point of Quality of service is good to the excellent advice and technology structure reengineering has a positive influence toward Quality of service. The more effective the technology structure reengineering, so the higher rate of service level of ITPC Busan will be.

\section{REFERENCES}

[1] M. Hammer, J. Champy, Reengineering the Corporation: A Manifesto for Business Revolution, Harper Collins Publisher, New York, 1995.

[2] J. Heizer, B. Render, Manajemen Operasi. Salemba 4, Jakarta, 2009.

[3] M. Hammer, S.A, Stanton, The Reenginering Revolution. Harper Collins Publisher, New York, 1995.

[4] S.Y, Herath, The Role of management accountant in business process reengineering, Department of Accounting and Finance, University of Wollongong, Australia, 1996. 
[5] A. Dwiyanto, Reformasi Birokrasi Publik di Indonesia. Gadjah Mada University Press, Yogyakarta, 2008.

[6] Moeheriono, Pengukuran Kinerja Berbasis Kinerja, PT. Raja Grafindo Persada, Jakarta, 2012

[7] D.C, Andrew, S.K, Stalick, Business Reengineering : The Survival Guide, Pearson Education, Florida, 1994.

[8] M. Myers, M. Larsen, BPR Success or Failure? A Bussiness Process Reengineering Project in The Financial Service Industry, Conference: Proceedings of the Eighteenth International Conference on Information Systems, Atlanta,1997.

[9] S. Zauhar, Birokrasi, Birokratisasi dan Post Bureaucracy, Universitas Brawijaya. Malang, 2005. 